\title{
Role of surgery in patients with early stage small-cell lung cancer
}

This article was published in the following Dove Press journal:

Cancer Management and Research

\author{
Aimei Pengl,* \\ Guoshu Li ${ }^{1} * *$ \\ Mengting Xiong ${ }^{2, *}$ \\ Shuanshuan Xie \\ Changhui Wang'
}

'Department of Respiratory Medicine, Shanghai Tenth People's Hospital, Tongji University, Shanghai 200072, People's Republic of China; ${ }^{2}$ Department of Respiratory Medicine, Pulmonary Hospital, Tongji University, Shanghai 200433, People's Republic of China

*These authors contributed equally to this work
Correspondence: Shuanshuan Xie; Changhui Wang

Department of Respiratory Medicine, Shanghai Tenth People's Hospital, Tongii University, No. 30I, Yanchang Middle Road, Jing'an District, Shanghai 200072,

People's Republic of China

Tel +8621 66301685

Fax +862166301685

Email xieshuanshuan@aliyun.com;

wang-chang-hui@hotmail.com
Purpose: Currently, systemic chemotherapy combined with thoracic radiation is the standard treatment for patients with small-cell lung cancer (SCLC). However, the treatment of early stage SCLC remains controversial. This study evaluated the survival outcomes of surgical treatments and the effect of adjuvant chemotherapy and radiotherapy on lung cancerspecific survival (LCSS) in patients with early stage SCLC.

Methods: Using the Surveillance, Epidemiology, and End Results registry, we identified 2,453 patients with early stage SCLC (1,295 women and 1,158 men) who had complete clinical information between 2004 and 2015. The Kaplan-Meier analysis was used to determine the propensity score based on the characteristics of patients with early stage SCLC. LCSS was compared between patients treated with surgery and non-surgery after adjusting, stratifying, or matching patients with early stage SCLC. In addition, we compared the effects of chemotherapy and radiotherapy on LCSS in patients with early stage SCLC.

Results: Overall, 687 (28.0\%) and 1,766 (72.0\%) patients with early stage SCLC did and did not undergo surgery, respectively. Kaplan-Meier analysis demonstrated a statistically significant difference in survival curves between the surgery and non-surgery groups (log-rank $p<0.001$ ). Compared with the non-surgery group, the LCSS of the surgery group was better (hazard ratio [HR]:0.494, 95\% confidence interval [CI]:0.415-0.587, $p<0.001$ ) in patients with early stage SCLC when using a Cox model for multivariate analysis. There was no statistically significant difference $(p=0.847)$ in LCSS between patients with early stage SCLC with and without chemotherapy in the multivariate analysis. Radiotherapy had favorable effects on LCSS (HR: 0.579 , 95\% CI: $0.500-0.671, p<0.001$ ) in patients with early stage SCLC using multivariate analysis.

Conclusions: Our study results suggest that LCSS conferred by surgery was higher than that conferred by non-surgery and that radiotherapy is associated with better survival in patients with early stage SCLC. This study findings should be confirmed in prospective studies.

Keywords: early stage small-cell lung cancer, surgery, lung cancer-specific survival, SEER, chemotherapy, radiotherapy

\section{Introduction}

Lung cancer is a serious threat to human health and its incidence has risen rapidly in recent years. According to statistical data, lung cancer was the second most common cancer (approximately 13\%) and the leading cause of tumor-related death (approximately 26\%) in the United States in 2016. ${ }^{1}$ Small-cell lung cancer (SCLC) is a pathological type, accounting for about $15 \%$ of all lung cancer. ${ }^{2}$ Due to its aggressive nature and early metastasis, approximately two-thirds of SCLC patients are diagnosed with advanced disease and have a poor prognosis. ${ }^{3}$ However, some 
patients are diagnosed at a stage in which their disease may be curable. ${ }^{4}$ Patients with early stage SCLC who underwent surgery had a reported five-year survival rate of $40 \%$ to $60 \%{ }^{5-9}$

Historically, SCLC was treated by surgery. However, the Medical Research Council performed a trial ${ }^{10}$ in the 1960s that demonstrated the poor survival of patients who underwent surgery. This outcome resulted in the abandonment of surgery and the use of chemotherapy as a standard method for SCLC treatment. Subsequently, two metaanalyses ${ }^{11,12}$ reported that systemic chemotherapy in combination with thoracic radiation improved survival, a treatment that has become the standard for patients with SCLC.

However, the treatment of SCLC remains controversial. Some institutions have reported good results in patients with early stage SCLC who received surgery. ${ }^{5,13}$ Other studies have reported favorable results in patients with stage III SCLC who be interfered with surgery.,14 Therefore, this study aimed to investigate the effects of surgical resection on lung cancer-specific survival (LCSS) in patients with early stage SCLC. We also analyzed the effect of adjuvant chemotherapy and radiotherapy on the LCSS in these patients.

\section{Methods}

\section{Data source}

The data used in this study were from the Surveillance, Epidemiology, and End Results (SEER) database. The SEER database is sponsored by the National Cancer Institute of the US and provides registry information on cancer including pathological type, patient survival, surgery, and adjuvant therapy since 1973.

\section{Study population}

We limited the cohort to patients with early stage SCLC diagnosed from 2004 to 2015. All early stage SCLC patients were staged using American Joint Committee on Cancer with stage I or IIa (stage T1-2N0M0) disease. Patients who underwent surgery were staged pathologically and those without surgery had clinic staging. Complete patient information was available in the SEER database.

\section{Covariates}

The baseline characteristics based on 17 covariates included age, sex, race, tumor size, TNM stage, tumor location, differentiated grade, laterality, surgery, radiotherapy, chemotherapy, insurance status, year of diagnosis, marital status, geographic region, high school education, and median household income. To better analyze the effects of adjuvant therapy on LCSS, we created a new covariate called adjuvant therapy, defined as patients who received one or both treatments (chemotherapy, radiotherapy or chemoradiotherapy).

\section{Statistical analyses}

All data were analyzed using IBM SPSS, version 20.0 (IBM Corp, Armonk, NY, USA). Kaplan-Meier analysis was used to compare survival between the surgery and non-surgery groups. Propensity score methods were used to control for potential differences in baseline characteristics of the included patients. Cox regression was performed to assess the balance of the baseline covariates of the two groups after adjusting for the estimated propensity scores.

\section{Results}

\section{Study cohort characteristics}

We identified 2,453 patients with early stage SCLC, of whom $687(28.0 \%)$ underwent surgery as a primary treatment and 1,766 (72.0\%) did not between 2004 and 2015 . Table 1 shows the baseline characteristics of all patients identified through the SEER database. The results of Kaplan-Meier analyses demonstrated statistically significant differences in LCSS between the two groups with regard to age $(p<0.001)$, sex $(p=0.007)$, tumor size $(p<0.001)$, TNM stage $(p<0.001)$, radiotherapy $(p=0.001)$, chemotherapy ( $p=0.026)$, insurance status $(p<0.001)$, adjuvant therapy $(p=0.007)$, and year of diagnosis $(p<0.001)$. However, no significant differences in LCSS were observed with respect to race $(p=0.396)$, tumor location $(p=0.698)$, differentiated grade $(p=0.063)$, laterality $(p=0.611)$, marital status $(p=0.426)$, geographic region $(p=0.069)$, high school education $(p=0.138)$, and median household income $(p=0.470)$ (Table 1).

A Cox model for multivariate analysis including the above significant covariates (TNM stage was excluded due to covariates tumor size and TNM stage linearly related) showed statistically significant differences for age $(p<0.001)$, sex $(p=0.008)$, tumor size $(p=0.002)$, surgery $(p<0.001)$, radiotherapy $(p<0.001)$, and year of diagnosis $(p<0.001)$. Covariates such as chemotherapy $(p=0.942)$, insurance status $(p=0.495)$, and adjuvant therapy $(p=0.839)$ did not differ significantly (Table 2 ). Subsequent analysis using a new Cox model including five covariates (age, sex, tumor size, surgery, and radiotherapy) revealed statistically 
Table I Baseline characteristics of patients treated with surgery or non-surgery in the Surveillance, Epidemiology and End Results (SEER) Program, 2004-20I5

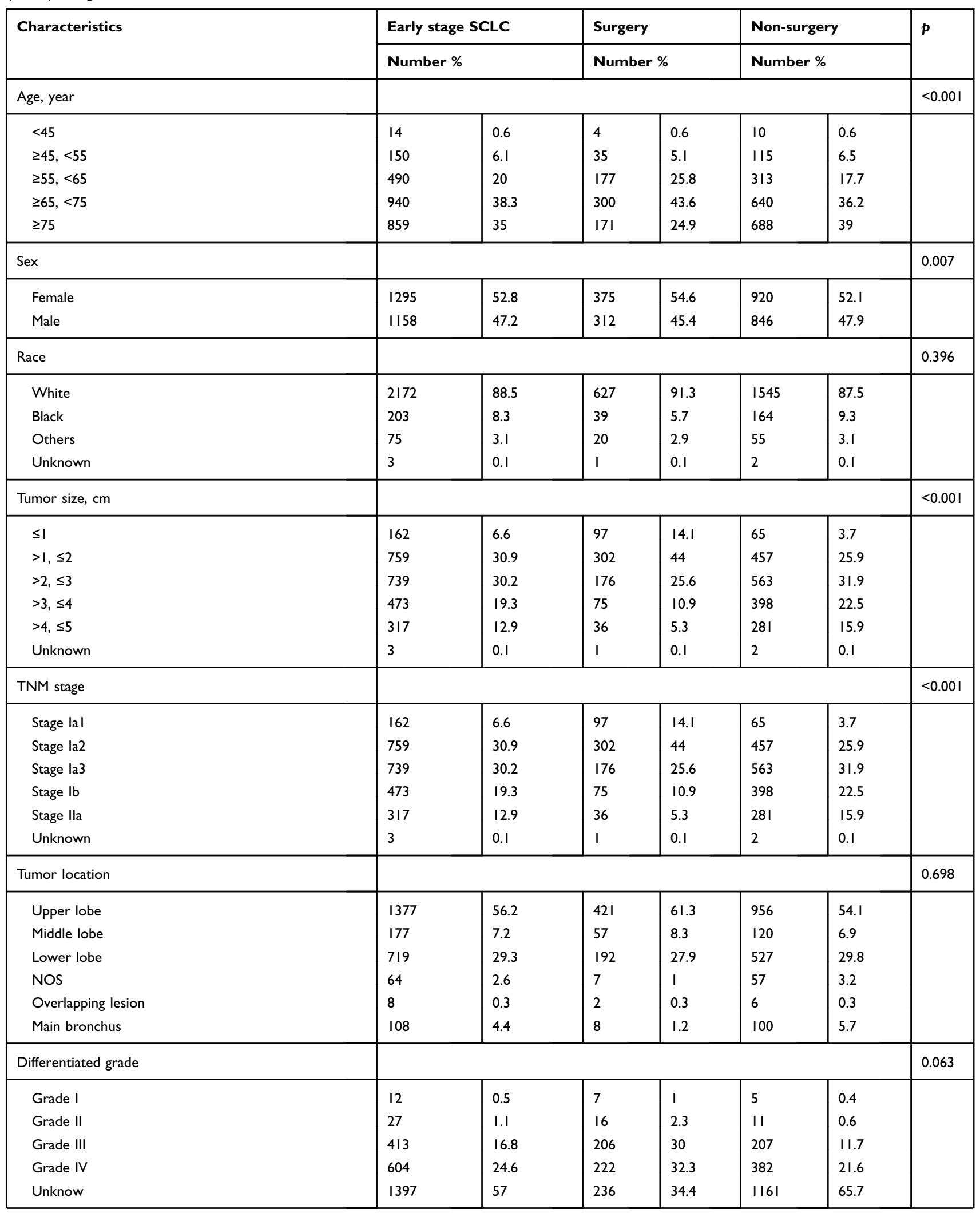


Table I (Continued).

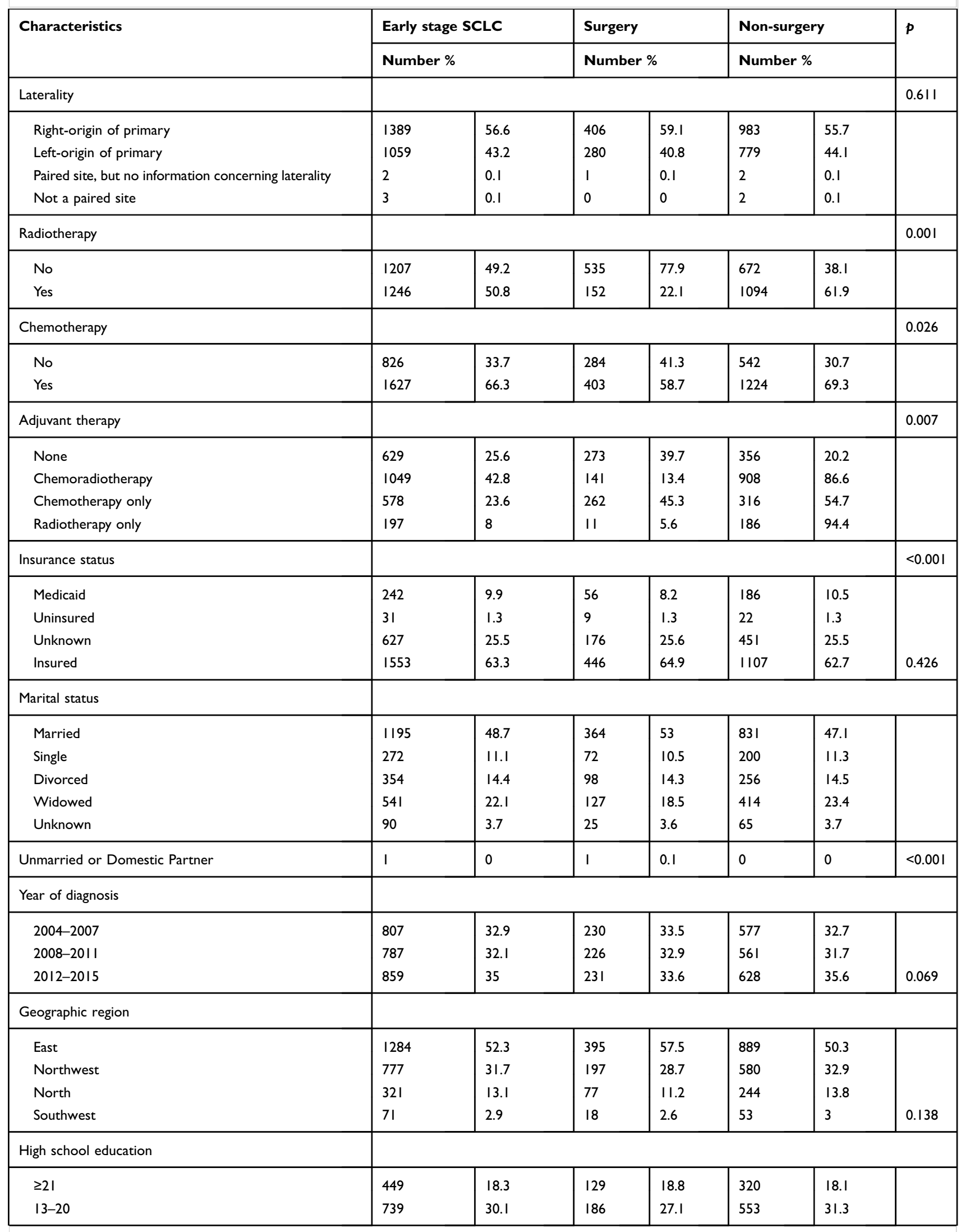

(Continued) 
Table I (Continued).

\begin{tabular}{|c|c|c|c|c|c|c|c|}
\hline \multirow{3}{*}{$\begin{array}{l}\text { Characteristics } \\
7-12\end{array}$} & \multirow{2}{*}{\multicolumn{2}{|c|}{$\begin{array}{l}\text { Early stage SCLC } \\
\text { Number \% }\end{array}$}} & \multirow{2}{*}{\multicolumn{2}{|c|}{$\begin{array}{l}\text { Surgery } \\
\text { Number \% }\end{array}$}} & \multirow{2}{*}{\multicolumn{2}{|c|}{$\begin{array}{l}\text { Non-surgery } \\
\text { Number \% }\end{array}$}} & \multirow{4}{*}{$\begin{array}{l}P \\
0.47\end{array}$} \\
\hline & & & & & & & \\
\hline & 1083 & 44.2 & 319 & 46.4 & 764 & 43.3 & \\
\hline$<7$ & 182 & 7.4 & 53 & 7.7 & 129 & 7.3 & \\
\hline \multicolumn{8}{|c|}{ Median household income (dollar, in tens) } \\
\hline$<38000$ & 221 & 9 & 69 & 10.1 & 152 & 8.6 & \\
\hline $38000-47999$ & 488 & 19.9 & 119 & 17.3 & 369 & 20.9 & \\
\hline $48000-62999$ & 942 & 38.4 & 250 & 36.4 & 692 & 39.2 & \\
\hline$>63000$ & 802 & 32.7 & 249 & 36.2 & 553 & 31.3 & \\
\hline
\end{tabular}

Abbreviations: SCLC, small-cell lung cancer; NOS, not otherwise specified.

significant differences for age $(p<0.001)$, sex $(p=0.014)$, tumor size $(p=0.006)$, surgery $(p<0.001)$, and radiotherapy $(p<0.001)$ (Table 3).

\section{Comparison of disease-specific mortality and median survival time between the surgery and non-surgery groups}

The overall lung cancer-specific mortality rate in patients with early stage SCLC was $35.8 \%$ (879/2453). The mortality rates were $35.2 \%(242 / 687)$ and $36.1 \%(637 / 1766)$ for the surgery and non-surgery groups, respectively. The overall median survival time for patients with early stage SCLC was 17 months. The median survival times in the surgery and non-surgery groups were 26 and 15 months, respectively (Table 4). Compared to that in the nonsurgery group, the crude hazard ratio (HR) and $95 \%$ confidence interval (CI) was $0.590(0.508-0.686, p<0.001)$ for the surgery group in patients with early stage SCLC. After adjusting for age, sex, tumor size, surgery, and radiotherapy, the HR $(95 \% \mathrm{CI})$ for the surgery group was 0.494 (0.415-0.587, $p<0.001)$ (Table 3 ). The median survival time and HR of the surgery group were significantly better than those in the non-surgery group.

\section{Kaplan-Meier analysis of disease-specific survival between the surgery and non-surgery groups}

Kaplan-Meier analysis revealed statistically significant differences in survival curves and log-rank tests between the two groups. Among all patients with early stage SCLC, the survival (log-rank $p<0.001)$ of the surgery group was better than that of the non-surgery group (Figure 1A). Similarly, the survival (log-rank $p<0.001$ ) of the surgery group was better than that of the non-surgery group in patients aged $\geq 75$ years (Figure 1B). The survival advantage $(\log$-rank $p<0.001)$ in the surgery group persisted in patients aged $<75$ years (Figure 1C). In addition, the survival (log-rank $p<0.001$ ) of the surgery group was better than that of the non-surgery group for patients with tumor size T1 $(\leq 3 \mathrm{~cm})$ (Figure 1D). The survival advantage (log-rank $p=0.002)$ in the surgery group persisted in patients with tumor size T2 $(3 \mathrm{~cm}<$ and $\leq 5 \mathrm{~cm})$ (Figure 1E). Our data demonstrated the significant effect of surgery on disease-specific survival in patients with early stage SCLC.

\section{Comparison of the effects of adjuvant therapy in patients with early stage SCLC} Kaplan-Meier analysis showed a statistically significant difference $(p=0.026)$ in the LCSS in patients with early stage SCLC who received chemotherapy (Table 1). However, this difference disappeared in the Cox model $(p=0.847)$ (Table 2). Similarly, there was a significant difference $(p=0.031)$ in LCSS in patients with early stage SCLC who received adjuvant therapy (Table 1), which also disappeared in the Cox model $(p=0.839)$ (Table 2).

Kaplan-Meier analysis also revealed a statistically significant difference $(p=0.001)$ in LCSS in patients with early stage SCLC who received radiotherapy by (Table 1). In a Cox model including nine covariates, the $\mathrm{HR}(95 \% \mathrm{CI})$ was 0.572 $(0.479-0.682, p<0.001)$ for patients who received radiotherapy compared to those without (Table 2). After adjusting for age, sex, tumor size, surgery, and radiotherapy, the HR $(95 \%$ CI) was $0.579(0.500-0.671, p<0.001)$ in patients who received radiotherapy (Table 3 ).

The effects of radiotherapy on LCSS are also shown in Table 6. The HR $(95 \% \mathrm{CI})$ of patients with radiotherapy was $0.804(0.704-0.918, p=0.001)$ compared to patients without radiotherapy. Similarly, compared to patients 
Table 2 Multivariate analysis using a cox proportional hazards model in patients with early stage SCLC

\begin{tabular}{|c|c|c|c|}
\hline \multirow[t]{2}{*}{ Variable } & \multicolumn{3}{|c|}{ Multivariable analysis $^{\mathrm{a}}$} \\
\hline & HR & $95 \% \mathrm{Cl}$ & $p$ \\
\hline Age, year & \multirow[b]{2}{*}{ Reference } & \multirow[b]{3}{*}{ I.208-20.374 } & $<0.001$ \\
\hline$<45$ & & & \\
\hline$\geq 45,<55$ & 4.961 & & 0.026 \\
\hline$\geq 55,<65$ & 5.008 & $1.238-20.257$ & 0.024 \\
\hline$\geq 65,<75$ & 5.618 & $|.39|-22.68 \mid$ & 0.015 \\
\hline$\geq 75$ & 7.381 & I.824-29.870 & 0.005 \\
\hline Sex & \multirow[b]{2}{*}{ Reference } & \multirow[b]{3}{*}{$1.050-1.374$} & \multirow[t]{3}{*}{0.008} \\
\hline Female & & & \\
\hline Male & 1.201 & & \\
\hline Tumor size, cm & Reference & \multirow[b]{2}{*}{$0.868-1.604$} & \multirow[t]{2}{*}{0.002} \\
\hline$\leq 1$ & \multirow{2}{*}{$\begin{array}{l}1.18 \\
1.217\end{array}$} & & \\
\hline$>1, \leq 2$ & & $0.893-1.658$ & 0.292 \\
\hline$>2, \leq 3$ & 1.346 & $0.975-1.858$ & 0.213 \\
\hline$>3, \leq 4$ & 1.77 & $|.268-2.47|$ & 0.071 \\
\hline$>4, \leq 5$ & \multirow[t]{2}{*}{1.192} & \multirow[t]{2}{*}{$0.163-8.735$} & 0.001 \\
\hline Unknown & & & 0.863 \\
\hline Surgery & \multirow{3}{*}{$\begin{array}{l}\text { Reference } \\
0.499\end{array}$} & \multirow{3}{*}{$0.420-0.594$} & \multirow[t]{3}{*}{$<0.00$ I } \\
\hline No & & & \\
\hline Yes & & & \\
\hline Radiotherapy & \multirow{3}{*}{$\begin{array}{l}\text { Reference } \\
0.552\end{array}$} & \multirow{3}{*}{$0.4 \mid I-0.742$} & $<0.001$ \\
\hline No & & & \\
\hline Yes & & & \\
\hline Chemotherapy & Reference & & 0.942 \\
\hline No & 0.993 & $0.822-1.200$ & \\
\hline Yes & Reference & & \\
\hline Adjuvant therapy & 1.035 & $0.742-1.445$ & 0.839 \\
\hline None & & & \\
\hline Chemoradiotherapy & Reference & & \\
\hline Insurance status & 1.288 & $0.724-2.290$ & 0.495 \\
\hline Medicaid & 0.869 & $0.621-1.215$ & \\
\hline Uninsured & 0.9 & $0.709-1.142$ & 0.39 \\
\hline Unknown & & & 0.411 \\
\hline Insured & Reference & $0.975-1.617$ & 0.386 \\
\hline Year of diagnosis & 1.255 & $1.828-3.075$ & $<0.001$ \\
\hline 2004-2007 & 2.371 & & \\
\hline 2008-20II & & & 0.078 \\
\hline $2012-2015$ & & & $<0.001$ \\
\hline
\end{tabular}

Notes: aMultivariate analysis for age, sex, tumor size, surgery, radiotherapy, chemotherapy, insurance status, adjuvant therapy and year of diagnosis.

Abbreviations: SCLC, small-cell lung cancer; HR, hazard ratio; $\mathrm{Cl}$, confidence interval.

without radiotherapy, the $\mathrm{HR}(95 \% \mathrm{CI})$ was 0.804 $(0.683-0.947, p=0.009)$ among patients aged $<75$ years. However, compared to patients without radiotherapy aged $\geq 75$ years, there was no significant difference $(p=0.102)$ in
LCSS. Among patients with T1 (tumor size $\leq 3 \mathrm{~cm}$ ), the HR $(95 \% \mathrm{CI})$ of patients who received radiotherapy was $0.830(0.703-0.980, p=0.028)$ compared to those without radiotherapy. Compared to patients without radiotherapy, the HR $(95 \% \mathrm{CI})$ of patients with radiotherapy was 0.705 $(0.565-0.880, p=0.002)$ in patients with $\mathrm{T} 2(3 \mathrm{~cm}<$ and $\leq 5 \mathrm{~cm})$. In addition, the HR $(95 \% \mathrm{CI})$ of patients with radiotherapy was $0.544(0.463-0.639, p<0.001)$ compared to those without radiotherapy or surgery. However, there was no statistically significant difference $(p=0.079)$ in LCSS regardless of radiotherapy among patients who underwent surgery (Table 5).

The effects of radiotherapy on the survival curves are shown in Figure 2. In patients with early stage SCLC, the survival curve $(\log$-rank $p<0.001)$ of patients with radiotherapy was better than that in those without radiotherapy (Figure 2A). However, there was no statistically significant difference in survival curve (log-rank $p>0.05$ ) between patients with and without radiotherapy among those aged $\geq 75$ years (Figure 2B). However, the survival curve (logrank $p<0.05$ ) of patients with radiotherapy was better than that of those without radiotherapy among those aged $<75$ years (Figure 2C). Among patients with T1 (tumor sizes $\leq 3 \mathrm{~cm})(\log$-rank $p<0.05)$ and T2 $(3 \mathrm{~cm}<$ and $\leq 5 \mathrm{~cm})$, the survival curves of patients with radiotherapy were better than those of patients without radiotherapy (logrank $p<0.05$ ) (Figure 2D and E). In patients with surgery, there was no significant difference in survival curves (logrank $p>0.05$ ) between patients with and without radiotherapy (Figure 2F). However, among those without surgery, the survival curve $(\log -$ rank $p<0.001)$ of patients with radiotherapy was better than that of those without radiotherapy (Figure 2G).

\section{Comparison of the effects of treatment combinations in patients with early stage SCLC}

According to the patient's adjuvant therapy plans, we divided the patients with early stage SCLC into four cohorts: patients with chemoradiotherapy (cohort 1), patients without any adjuvant therapy (cohort 2), patients with chemotherapy only (cohort 3) and patients with chemoradiotherapy plus without any adjuvant therapy (cohort 4). Subsequently, we set up treatment combinations: non-surgery plus chemoradiotherapy group and surgery plus chemoradiotherapy group in cohort 1 , non-surgery plus no adjuvant therapy group and surgery plus no adjuvant therapy group in cohort 2 , non- 
Table 3 Univariable and multivariable analyses on LCSS in patients with early stage SCLC

\begin{tabular}{|c|c|c|c|c|c|c|}
\hline \multirow[t]{2}{*}{ Variable } & \multicolumn{3}{|c|}{ Univariable analysis } & \multicolumn{3}{|c|}{ Multivariable analysis $^{a}$} \\
\hline & HR & $95 \% \mathrm{Cl}$ & $p$ & HR & $95 \% \mathrm{Cl}$ & $p$ \\
\hline Age, year & & & $<0.001$ & & & $<0.001$ \\
\hline$<45$ & Reference & & & Reference & & \\
\hline$\geq 45,<55$ & 4.346 & $1.061-17.796$ & 0.041 & 4.477 & $|.092-| 8.35 \mid$ & 0.037 \\
\hline$\geq 55,<65$ & 4.158 & $|.03|-|6.77|$ & 0.045 & 4.615 & $1.143-18.638$ & 0.032 \\
\hline$\geq 65,<75$ & 4.695 & $1.168-18.878$ & 0.029 & 5.418 & $1.345-21.820$ & 0.017 \\
\hline$\geq 75$ & 6.492 & $1.613-26.131$ & 0.008 & 6.9 & $1.7 \mid I-27.826$ & 0.007 \\
\hline Sex & & & 0.007 & & & 0.014 \\
\hline Female & Reference & & & Reference & & \\
\hline Male & 1.199 & $1.050-1.370$ & & 1.184 & $1.035-1.354$ & \\
\hline Tumor size, $\mathrm{cm}$ & & & $<0.001$ & & & 0.006 \\
\hline$\leq 1$ & Reference & & & Reference & & \\
\hline$>1, \leq 2$ & 1.299 & $0.959-1.759$ & 0.091 & 1.183 & $0.870-1.607$ & 0.284 \\
\hline$>2, \leq 3$ & 1.363 & $1.006-1.847$ & 0.045 & 1.175 & $0.863-1.600$ & 0.307 \\
\hline$>3, \leq 4$ & 1.597 & I.167-2.187 & 0.003 & 1.319 & $0.956-1.820$ & 0.092 \\
\hline$>4, \leq 5$ & 1.963 & $1.422-2.710$ & 0 & 1.685 & $1.208-2.349$ & 0.002 \\
\hline Unknown & 1.129 & $0.156-8.178$ & 0.904 & 1.14 & $0.156-8.315$ & 0.897 \\
\hline Surgery & & & $<0.001$ & & & $<0.001$ \\
\hline No & Reference & & & Reference & & \\
\hline Yes & 0.59 & $0.508-0.686$ & & 0.494 & $0.415-0.587$ & \\
\hline Radiotherapy & & & 0.001 & & & $<0.001$ \\
\hline No & Reference & & & Reference & & \\
\hline Yes & 0.804 & $0.704-0.918$ & & 0.579 & $0.500-0.67 \mid$ & \\
\hline
\end{tabular}

Notes: ${ }^{a}$ Multivariate analysis for age, sex, tumor size, radiotherapy, surgery and chemotherapy.

Abbreviations: LCSS, lung cancer-specific survival; SCLC, small-cell lung cancer; HR, hazard ratio; $\mathrm{Cl}$, confidence interval.

Table 4 Association with cancer-specific mortality and median survival time among patient groups (SEER database, 2004-20I5)

\begin{tabular}{|l|l|l|}
\hline Group & Mortality, \% (n/N) & $\begin{array}{l}\text { Median survival time } \\
\text { (months) }\end{array}$ \\
\hline Overall & $35.8 \%(879 / 2453)$ & 17 \\
Non-surgery & $35.2 \%(242 / 687)$ & 15 \\
Surgery & $36.1 \%(637 / 1766)$ & 26 \\
\hline
\end{tabular}

Abbreviations: SEER, Surveillance, Epidemiology and End Results.

surgery plus chemotherapy only group and surgery plus chemotherapy only group in cohort 3 as well as nonsurgery plus chemoradiotherapy group and surgery plus no adjuvant therapy group in cohort 4 . In all cohorts, there were significant differences in survival curves and log-rank tests between the two groups in the same cohort (Figure 3). The survival curve (log-rank $p<0.001)$ of the surgery plus chemoradiotherapy group was better than that of the non-surgery plus chemoradiotherapy group in cohort 1 (Figure 3A). Similarly, the survival curve (log-rank $p<0.001)$ of the surgery plus no adjuvant therapy group was better than that of the non-surgery plus no adjuvant therapy group in cohort 2 (Figure 3B), and the survival curve (log-rank $p<0.001)$ of the surgery plus chemotherapy only group was better than that of the non-surgery plus chemotherapy only group in cohort 3 (Figure 3C). In addition, the survival curve (log-rank $p=0.005$ ) of the surgery plus no adjuvant therapy group was also better than that of the non-surgery plus chemoradiotherapy group in cohort 4 (Figure 3D).

Analogous results were showed in Table 7 by univariable analysis. Compared to the non-surgery plus chemoradiotherapy group, the HR $(95 \% \mathrm{CI})$ of the surgery plus chemoradiotherapy group was $0.581 \quad(0.429-0.787$, $p<0.001)$ in cohort 1 . The HR $(95 \% \mathrm{CI})$ of the surgery plus no adjuvant therapy group was $0.401(0.300-0.536$, $p<0.001)$ compared to the non-surgery plus no adjuvant therapy group in cohort 2 . The HR $(95 \% \mathrm{CI})$ of the surgery plus chemotherapy only group was $0.462(0.353-0.605$, $p<0.001)$ compared to the non-surgery plus chemotherapy only group in cohort 3 . The HR $(95 \% \mathrm{CI})$ of the surgery plus no adjuvant therapy group was $0.709(0.557-0.903$, 
A

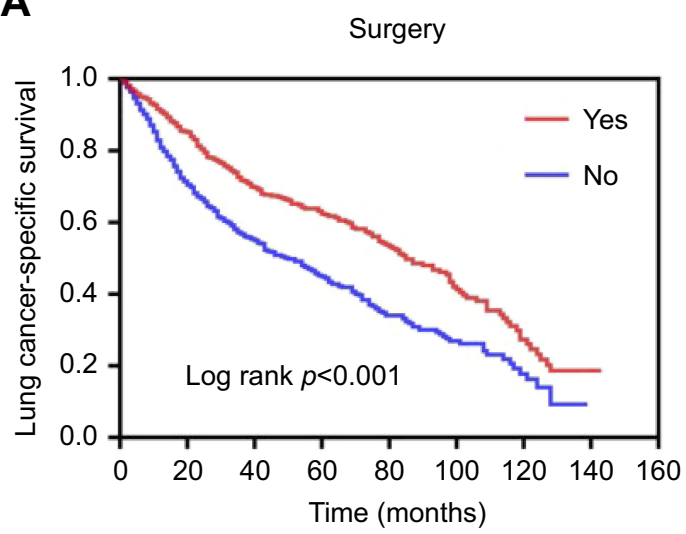

C

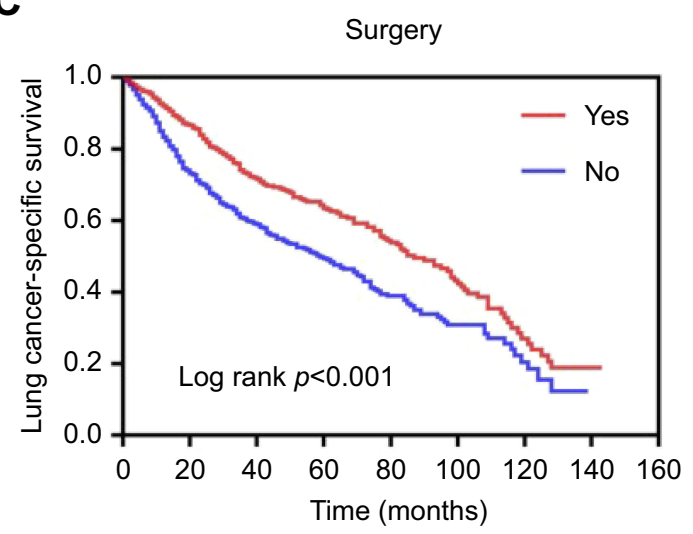

E

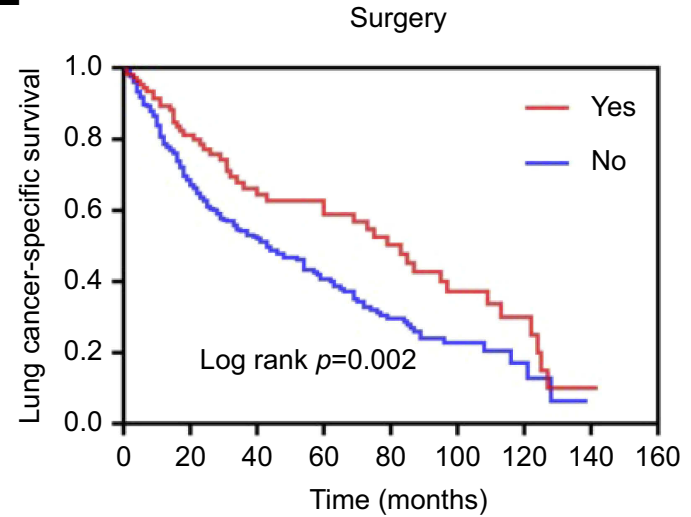

B

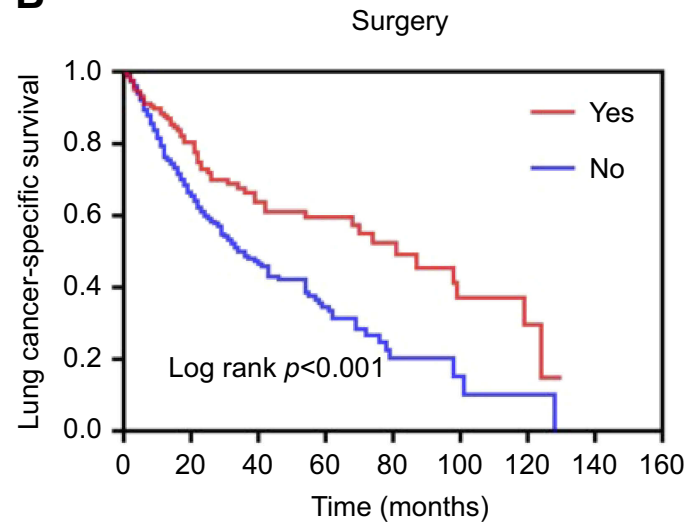

D

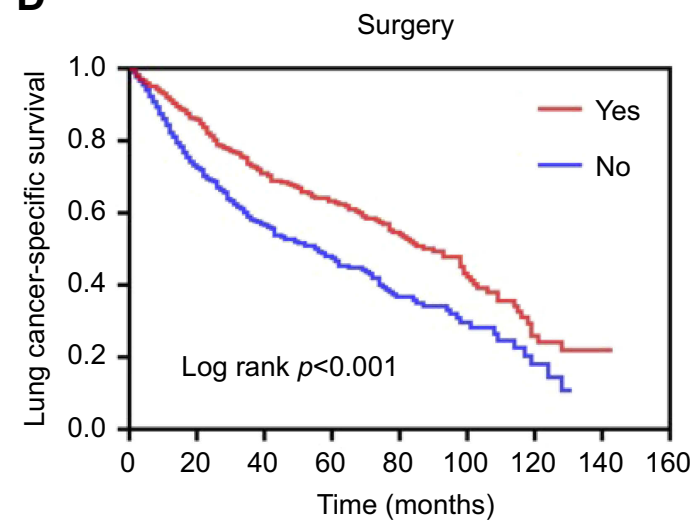

Figure I Survival curves based on Kaplan-Meier analysis comparing treatment with surgery versus non-surgery. (A) LCSS ( $p<0.001)$ in patients with early stage SCLC; (B) LCSS $(p<0.00 \mathrm{I})$ in patients with age $\geq 75$ years; (C) LCSS $(p<0.00 \mathrm{I})$ in patients with age $<75$ years; (D) LCSS ( $p<0.00 \mathrm{I})$ in patients with tumor size TI (sizes $\leq 3 \mathrm{~cm})$; (E) LCSS $(p=0.002)$ in patients with tumor size $\mathrm{T} 2(3 \mathrm{~cm}<$ sizes $\leq 5 \mathrm{~cm})$.

Abbreviations: LCSS, lung cancer-specific survival; SCLC, small-cell lung cancer.

$p=0.005)$ compared to the non-surgery plus chemoradiotherapy group in cohort 4 .

\section{Discussion}

Currently, chemoradiotherapy is the standard treatment for early stage SCLC, providing a median overall survival of
16-20 months. ${ }^{15,16}$ However, the optimal treatment of early stage SCLC remains controversial. An increasing number of studies suggest that surgical treatment can improve survival outcomes in patients with SCLC, especially in early stage disease. .,7,13,14,17-21 $^{\text {Retrospective }}$ studies have reported favorable outcomes for surgery in 
Table 5 Comparison of the effects of surgery (yes vs no) on LCSS in patients groups by univariate analysis

\begin{tabular}{|l|l|l|l|l|}
\hline \multirow{2}{*}{ Group } & \multirow{2}{*}{ Number } & \multicolumn{3}{|l|}{ Univariable analysis } \\
\cline { 3 - 5 } & & HR & $\mathbf{9 5 \% C l}$ & $\mathbf{P}$ \\
\hline All patients & 2453 & 0.590 & $0.508-0.686$ & $<0.001$ \\
Age 275 & 859 & 0.529 & $0.393-0.712$ & $<0.001$ \\
Age $<75$ & 1594 & 0.639 & $0.536-0.763$ & $<0.001$ \\
Size $\leq 3$ & 1660 & 0.612 & $0.512-0.730$ & $<0.001$ \\
$3<$ size $\leq 5$ & 790 & 0.610 & $0.445-0.836$ & 0.002 \\
\hline
\end{tabular}

Abbreviations: LCSS, lung cancer-specific survival; $\mathrm{HR}$, hazard ratio; $\mathrm{Cl}$, confidence interval.

Table 6 Comparison of the effects of radiotherapy (yes vs no) on LCSS in patients groups by univariate analysis

\begin{tabular}{|l|l|l|l|l|}
\hline \multirow{2}{*}{ Group } & \multirow{2}{*}{ Number } & \multicolumn{3}{|l|}{ Univariable analysis } \\
\cline { 3 - 5 } & & HR & $\mathbf{9 5 \% C l}$ & $\mathbf{p}$ \\
\hline All patients & 2453 & 0.804 & $0.704-0.918$ & 0.001 \\
Age 275 & 859 & 0.827 & $0.659-1.038$ & 0.102 \\
Age $<75$ & 1594 & 0.804 & $0.683-0.947$ & 0.009 \\
Size $\leq 3$ & 1660 & 0.830 & $0.703-0.980$ & 0.028 \\
$3<$ size $\leq 5$ & 790 & 0.705 & $0.565-0.880$ & 0.002 \\
Surgery & 687 & 0.761 & $0.560-1.032$ & 0.079 \\
Non-surgery & 1766 & 0.544 & $0.463-0.639$ & $<0.001$ \\
\hline
\end{tabular}

Abbreviations: LCSS, lung cancer-specific survival; $\mathrm{HR}$, hazard ratio; $\mathrm{Cl}$, confidence interval.

patients with stage I SCLC. ${ }^{22,23}$ A growing number of patients with early stage SCLC receive surgical treatment, resulting in a favorable overall median survival of 29-91 months. ${ }^{24-27}$ The present study evaluated the survival outcomes of surgery versus non-surgery in patients with early stage SCLC, finding that surgery resulted in a better LCSS than that of non-surgery. To further analyze the effect of surgery on LCSS in elderly patients with early stage SCLC, we divided the age covariates into $\geq 75$ and $<75$ years. The LCSS of patients receiving surgical treatment was better than that of non-surgery in patients aged $\geq 75$ years. Better survival was also observed in surgical patients aged $<75$ years than that in those without surgery. We also analyzed the effect of surgery on LCSS in patients with early stage SCLC with varying tumor sizes. We divided the patients into T1 $(\leq 3 \mathrm{~cm})$ and T2 $(3 \mathrm{~cm}<$ and $\leq 5 \mathrm{~cm}$ ) based on tumor size. Our results showed a superior LCSS in patients with surgery compared to non-surgery for both $\mathrm{T} 1$ and $\mathrm{T} 2$. Our results show that surgical treatment is superior to non-surgical in patients with early stage
SCLC. This result is consistent with those of the above studies.

At present, chemotherapy is the main treatment for early stage SCLC. We analyzed the effect of chemotherapy on LCSS in patients with early stage SCLC. Univariate analysis revealed statistically significant differences in LCSS between chemotherapy and nonchemotherapy patients with early stage SCLC. However, a Cox model for multivariate analysis indicated no statistically significant difference in LCSS between these groups. In addition, we defined one or two rounds of chemotherapy and radiotherapy as adjuvant therapy. We found a significant difference in univariate analysis, which disappeared in multivariate analysis. According to these outcomes, chemotherapy did not provide significant survival benefits for patients with early stage SCLC. This result may provide a reference for clinicians to select appropriate treatment methods for these patients.

Because SCLC is radiosensitive, radiotherapy can provide local control for patients with SCLC. ${ }^{4}$ We analyzed the effect of radiotherapy on LCSS in patients with early stage SCLC. In univariate analysis, the LCSS of patients with radiotherapy was better than that in non-radiotherapy patients. A Cox model for multivariate analysis (included covariates: age, sex, tumor size, surgery, and radiotherapy) also revealed a better LCSS in patients with radiotherapy than that in non-radiotherapy patients. These results suggest that radiotherapy has a significant effect on LCSS in patients with early stage SCLC. The patients were further divided into groups according to age $(\geq 75$ or $<75$ years), tumor size (T1 or T2), and surgery (yes or no) to analyze the effects of radiotherapy on LCSS in univariate analysis. Compared to that in nonradiotherapy patients, the LCSS of patients with radiotherapy was significantly better among those aged $<75$ years. Similarly, the LCSS of patients with radiotherapy was significantly better than that in those without radiotherapy and without surgery. However, among patients aged $\geq 75$ years or with surgery, there was no advantage for radiotherapy compared to nonradiotherapy. In addition, radiotherapy can provide a benefit in LCSS for radiotherapy patients, whether $\mathrm{T} 1$ or $\mathrm{T} 2$.

Patients with early stage SCLC might receive multiple treatments including surgery, radiotherapy and chemotherapy. 
A

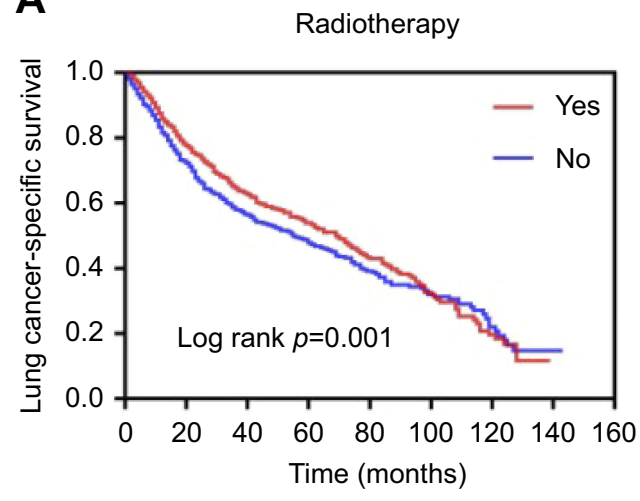

C

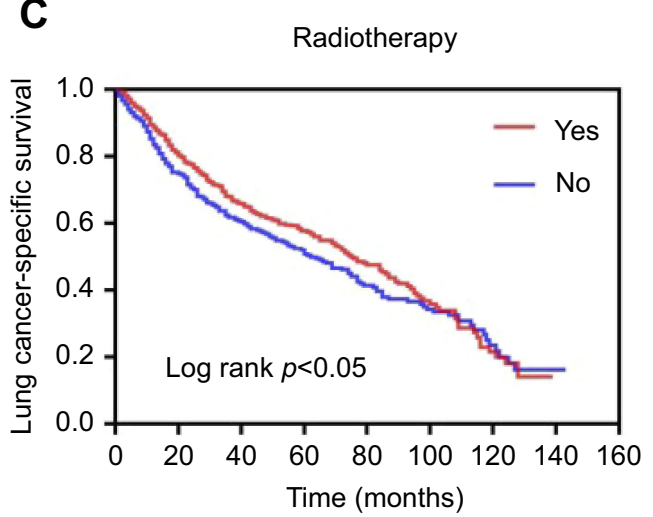

E

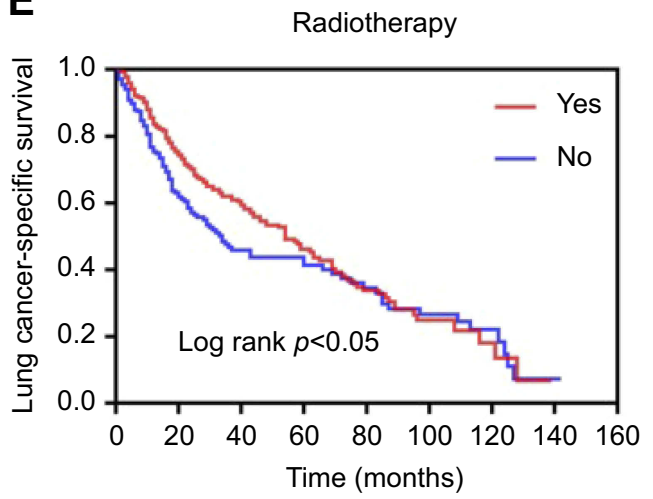

G

Radiotherapy

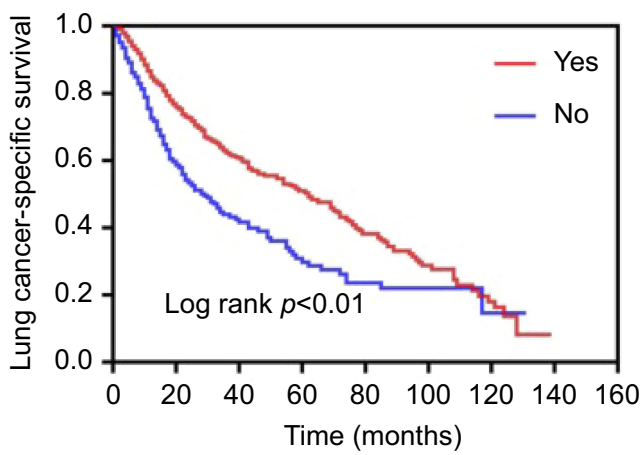

B

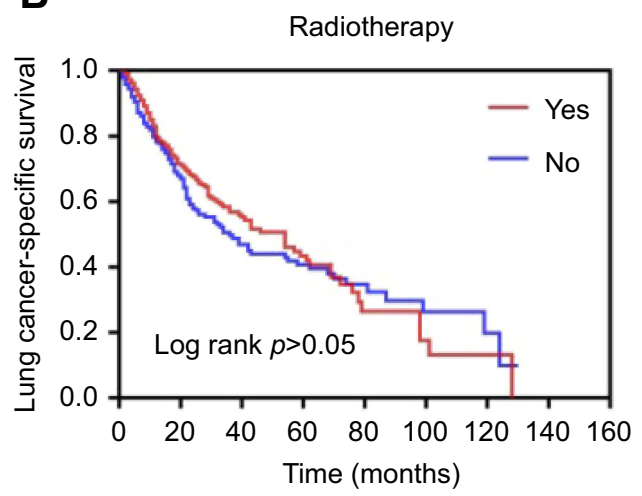

D

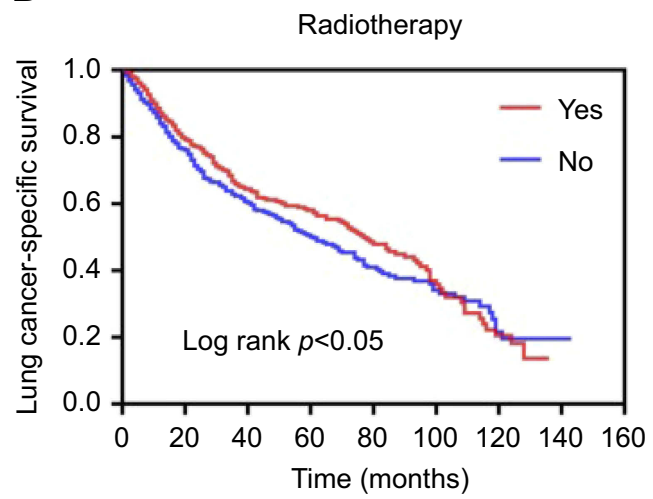

F
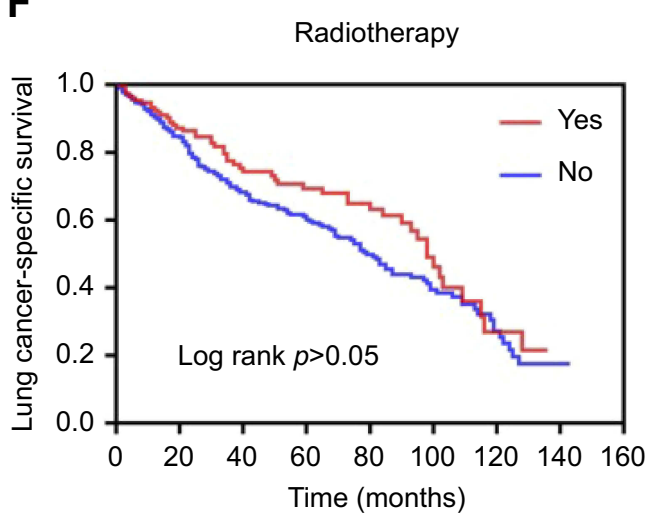

Figure 2 Comparison of the effects of radiotherapy on LCSS based on Kaplan-Meier analysis. (A) LCSS ( $p=0.00 \mathrm{I})$ in patients with early stage SCLC; (B) LCSS ( $p>0.05)$ in patients with age $\geq 75$ years; (C) LCSS $(p<0.05)$ in patients with age $<75$ years; (D) LCSS $(p<0.05)$ in patients with TI (tumor sizes $\leq 3 \mathrm{~cm})$; $(\mathbf{E})$ LCSS $(p<0.05)$ in patients with T2 $(3 \mathrm{~cm}<$ sizes $\leq 5 \mathrm{~cm})$; (F) LCSS $(p>0.05)$ in patients with surgery; $(\mathbf{G})$ cancer-specific survival $(p<0.00 \mathrm{I})$ in patients with non-surgery. Abbreviations: LCSS, lung cancer-specific survival; SCLC, small-cell lung cancer. 


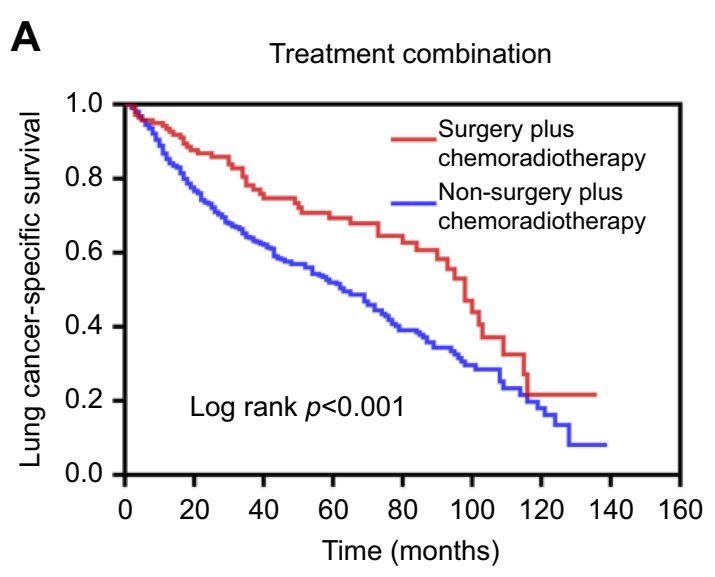

C

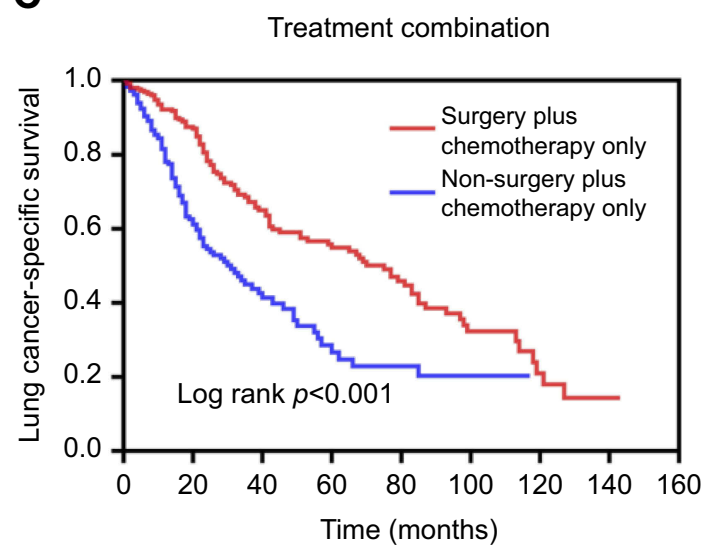

B

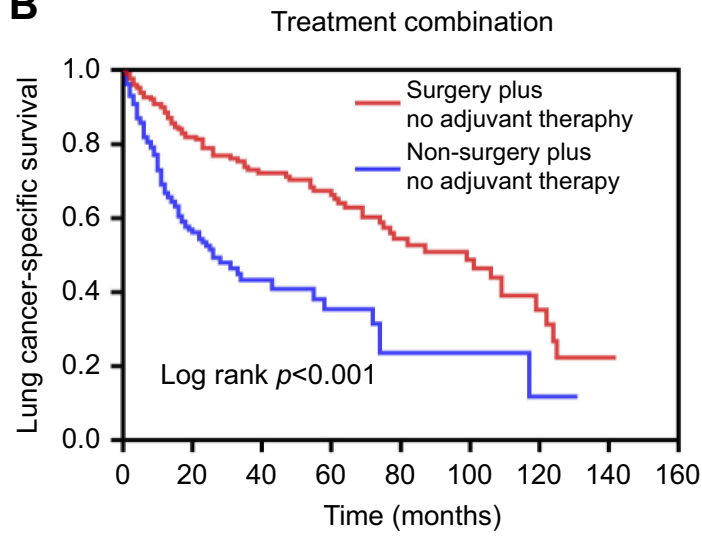

D

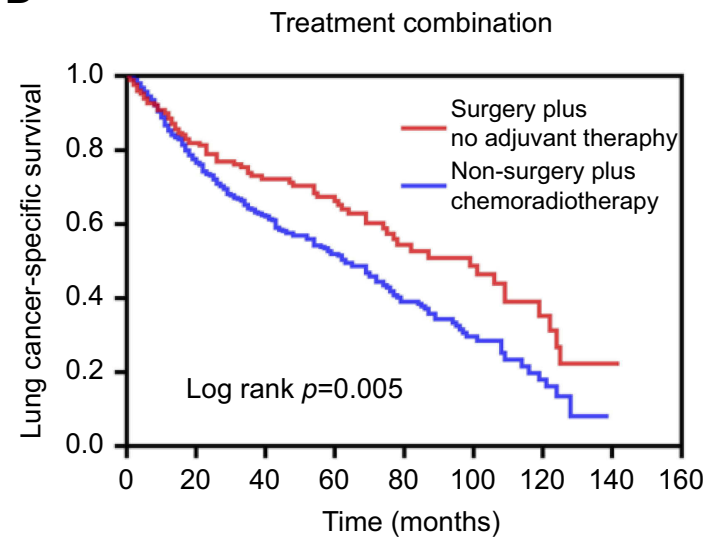

Figure 3 Comparison of the effects of treatment combinations in patients with early stage SCLC. (A) LCSS ( $p<0.00 \mathrm{I})$ in patients with chemoradiotherapy; (B) LCSS $(p<0.00 \mathrm{I})$ in patients without any adjuvant therapy; (C) LCSS $(p<0.00 \mathrm{I})$ in patients with chemotherapy only; (D) LCSS $(p=0.005)$ in patients with chemoradiotherapy plus without any adjuvant therapy.

Abbreviations: SCLC, small-cell lung cancer; LCSS, lung cancer-specific survival.

Therefore, it was necessary to further discuss the significance of surgery in different treatment combinations. Due to the small number of patients undergoing surgery plus radiotherapy, we did not discuss it further. Our results showed that the combination comprising surgery was superior to the combination without surgery on LCSS in the same cohort. Moreover, surgical treatment was superior to chemoradiotherapy in patients with early stage SCLC (Figure 3D, Table 7). This study further indicates that surgical treatment is a better option for patients with early stage SCLC.

Due to its retrospective design, our study has some limitations. One is the lack of information showing the status of performance or other indicators of the patient's physical condition. Another limitation is the lack of specific treatment information for the patient, such as chemotherapy regimen, radiation dose and method, and the surgical procedure. However, with the inclusion of 18 covariates and nearly 2,500 patients in our cohort, the present study represents a wellbalanced analysis between surgery and non-surgical methods. Thus, in the absence of data from prospective trials, our findings provide useful information for the management of patients with early stage SCLC.

In summary, the prognosis of patients with early stage SCLC was related to a variety of factors. According to the results of our study, surgery was superior to non-surgery in patients with early stage SCLC; therefore, we recommend surgical resection as the more favorable choice. In addition, because radiotherapy may be beneficial for patients with early stage SCLC, it should be recommended, especially in patients not undergoing surgery and aged $<75$ years. Understanding this information is critical to the prognosis of patients with early stage SCLC and our findings help in determining the best treatment strategies for these patients. 
Table 7 Comparison of the effects of treatment combinations on LCSS in patients with early stage SCLC by univariate analysis

\begin{tabular}{|c|c|c|c|c|}
\hline \multirow[t]{2}{*}{ Treatment Combination } & \multirow[t]{2}{*}{ Number } & \multicolumn{3}{|c|}{ Univariable Analysis } \\
\hline & & HR & $95 \% \mathrm{Cl}$ & $p$ \\
\hline \multicolumn{5}{|l|}{ Cohort I } \\
\hline \multicolumn{5}{|l|}{ Non-surgery plus } \\
\hline \multirow{2}{*}{\multicolumn{5}{|c|}{ Surgery plus }} \\
\hline & & & & \\
\hline Chemoradiotherapy & $|4|$ & 0.581 & $0.429-0.787$ & $<0.001$ \\
\hline \multicolumn{5}{|l|}{ Cohort 2} \\
\hline \multicolumn{5}{|l|}{ Non-surgery plus } \\
\hline No adjuvant therapy & 356 & Reference & & \\
\hline \multicolumn{5}{|l|}{ Surgery plus } \\
\hline No adjuvant therapy & 273 & 0.401 & $0.300-0.536$ & $<0.001$ \\
\hline \multicolumn{5}{|l|}{ Cohort 3} \\
\hline \multicolumn{5}{|l|}{ Non-surgery plus } \\
\hline \multirow{2}{*}{\multicolumn{5}{|c|}{ Surgery plus }} \\
\hline & & & & \\
\hline Chemotherapy only & 262 & 0.462 & $0.353-0.605$ & $<0.001$ \\
\hline \multicolumn{5}{|l|}{ Cohort 4} \\
\hline \multicolumn{5}{|l|}{ Non-surgery plus } \\
\hline Chemoradiotherapy & 908 & Reference & & \\
\hline \multicolumn{5}{|l|}{ Surgery plus } \\
\hline No adjuvant therap & 273 & 0.709 & $0.557-0.903$ & 0.005 \\
\hline
\end{tabular}

Abbreviations: LCSS, lung cancer-specific survival; SCLC, small-cell lung cancer; HR, hazard ratio; $\mathrm{Cl}$, confidence interval.

\section{Abbreviation list}

SCLC, small-cell lung cancer; SEER, Surveillance, Epidemiology and End Results; LCSS, lung cancer-specific survival; HR, hazard ratio; CI, confidence interval; NOS, not otherwise specified.

\section{Ethical approval}

All procedures performed in studies involving human participants were in accordance with the ethical standards of the institutional and/or national research committee and with the 1964 Declaration of Helsinki and its later amendments or comparable ethical standards. For this type of study, formal consent is waived.

\section{Acknowledgments}

We would like to thank all the staff of the National Cancer Institute for their efforts in the SEER program. This work was supported by the National Natural Science Foundation of China ([NSFC] nos. 81472180, 81802262), Shanghai Tenth Hospital's improvement plan for NSFC (nos. 04.03.17.032, 04.01.18. 048), the Fundamental Research Funds for the Central Universities (nos. 22120180584) and
Shanghai Chongming district "sustainable development science and technology" (nos. CKY2019-9).

\section{Disclosure}

The authors declare there are no potential conflicts of interest related to this study.

\section{References}

1. Siegel RL, Miller KD, Jemal A. Cancer statistics, 2016. CA Cancer J Clin. 2016;66:7-30. doi:10.3322/caac.21332

2. Che K, Shen H, Qu X, et al. Survival outcomes for patients with surgical and non-surgical treatments in stages I-III small-cell lung cancer. J Cancer. 2018;9:1421-1429. doi:10.7150/jca.23583

3. Shepherd FA, Crowley J, Van Houtte P, et al. The International Association for the Study of Lung Cancer lung cancer staging project: proposals regarding the clinical staging of small cell lung cancer in the forthcoming (seventh) edition of the tumor, node, metastasis classification for lung cancer. $J$ Thorac Oncol. 2007;2:1067-1077. doi:10.1097/JTO.0b013e31815bdc0d

4. Almquist D, Mosalpuria K, Ganti AK. Multimodality therapy for limited-stage small-cell lung cancer. $J$ Oncol Pract. 2016;12:111-117. doi:10.1200/JOP.2015.009068

5. Inoue M, Miyoshi S, Yasumitsu T, et al. Surgical results for small cell lung cancer based on the new TNM staging system. Thoracic Surgery Study Group of Osaka University, Osaka, Japan. Ann Thorac Surg. 2000;70:1615-1619. 
6. Rostad H, Naalsund A, Jacobsen R, et al. Small cell lung cancer in Norway. Should more patients have been offered surgical therapy? Eur J Cardiothorac Surg. 2004;26:782-786. doi:10.1016/j.ejcts.2004.06.011

7. Brock MV, Hooker CM, Syphard JE, et al. Surgical resection of limited disease small cell lung cancer in the new era of platinum chemotherapy: its time has come. J Thorac Cardiovasc Surg. 2005;129:64-72. doi:10.1016/j.jtcvs.2004.08.022

8. Lim E, Belcher E, Yap YK, Nicholson AG, Goldstraw P. The role of surgery in the treatment of limited disease small cell lung cancer: time to reevaluate. $J$ Thorac Oncol. 2008;3:1267-1271. doi:10.1097/ JTO.0b013e318189a860

9. Schneider BJ, Saxena A, Downey RJ. Surgery for early-stage small cell lung cancer. J Natl Compr Canc Netw. 2011;9:1132-1139.

10. Fox W, Scadding JG. Medical Research Council comparative trial of surgery and radiotherapy for primary treatment of small-celled or oat-celled carcinoma of bronchus. Ten-year follow-up. Lancet. 1973;2:63-65. doi:10.1016/s0140-6736(73)93260-1

11. Pignon JP, Arriagada R, Ihde DC, et al. A meta-analysis of thoracic radiotherapy for small-cell lung cancer. $N$ Engl J Med. 1992;327:1618-1624. doi:10.1056/NEJM199212033272302

12. Warde P, Payne D. Does thoracic irradiation improve survival and local control in limited-stage small-cell carcinoma of the lung? A meta-analysis. J Clin Oncol. 1992;10:890-895. doi:10.1200/JCO.1992.10.6.890

13. Lewiński T, Zuławski M, Turski C, Pietraszek A. Small cell lung cancer I-III A: cytoreductive chemotherapy followed by resection with continuation of chemotherapy. Eur J Cardiothorac Surg. 2001;20:391-398. doi:10.1016/s1010-7940(01)00787-4

14. Tsuchiya R, Suzuki K, Ichinose Y, et al. Phase II trial of postoperative adjuvant cisplatin and etoposide in patients with completely resected stage I-IIIa small cell lung cancer: the Japan Clinical Oncology Lung Cancer Study Group Trial (JCOG9101). J Thorac Cardiovasc Surg. 2005;129:977-983. doi:10.1016/j.jtcvs.2004.05.030

15. Schild SE, Bonner JA, Hillman S, et al. Results of a phase II study of high-dose thoracic radiation therapy with concurrent cisplatin and etoposide in limited-stage small-cell lung cancer (NCCTG 95-20-53). J Clin Oncol. 2007;25:3124-3129. doi:10.1200/JCO.2006.09.9606

16. Chen J, Jiang R, Garces YI, et al. Prognostic factors for limited-stage small cell lung cancer: a study of 284 patients. Lung Cancer. 2010;67:221-226. doi:10.1016/j.lungcan.2009.04.006

17. Shields TW, Higgins GA Jr, Matthews MJ, Keehn RJ. Surgical resection in the management of small cell carcinoma of the lung. J Thorac Cardiovasc Surg. 1982;84:481-488.
18. Shepherd FA, Ginsberg RJ, Patterson GA, Evans WK, Feld R. A prospective study of adjuvant surgical resection after chemotherapy for limited small cell lung cancer. A University of Toronto Lung Oncology Group study. J Thorac Cardiovasc Surg. 1989;97:177-186.

19. Shepherd FA, Ginsberg RJ, Feld R, Evans WK, Johansen E. Surgical treatment for limited small-cell lung cancer. The University of Toronto Lung Oncology Group experience. J Thorac Cardiovasc Surg. 1991;101:385-393.

20. Eberhardt W, Stamatis G, Stuschke M, et al. Prognostically orientated multimodality treatment including surgery for selected patients of small-cell lung cancer patients stages IB to IIIB: long-term results of a phase II trial. Br J Cancer. 1999;81:1206-1212. doi:10.1038/sj. bjc. 6690830

21. Lüchtenborg M, Riaz SP, Lim E, et al. Survival of patients with small cell lung cancer undergoing lung resection in England, 1998-2009. Thorax. 2014;69:269-273. doi:10.1136/thoraxjnl-2013-203884

22. Schreiber D, Rineer J, Weedon J, et al. Survival outcomes with the use of surgery in limited-stage small cell lung cancer: should its role be re-evaluated? Cancer. 2010;116:1350-1357. doi:10.1002/ cncr. 24853

23. Yu JB, Decker RH, Detterbeck FC, Wilson LD. Surveillance epidemiology and end results evaluation of the role of surgery for stage I small cell lung cancer. $J$ Thorac Oncol. 2010;5:215-219. doi:10.11097/JTO.0b013e3181cd3208

24. Varlotto JM, Recht A, Flickinger JC, Medford-Davis LN, Dyer AM, DeCamp MM. Lobectomy leads to optimal survival in early-stage small cell lung cancer: a retrospective analysis. J Thorac Cardiovasc Surg. 2011;142:538-546. doi:10.1016/j.jtcvs.2010.11.062

25. Zhu H, Zhou Z, Xue Q, Zhang X, He J, Wang L. Treatment modality selection and prognosis of early stage small cell lung cancer: retrospective analysis from a single cancer institute. Eur J Cancer Care (Engl). 2013;22:789-796. doi:10.1111/ecc.12082

26. Yokouchi H, Ishida T, Yamazaki S, et al. Prognostic impact of clinical variables on surgically resected small-cell lung cancer: results of a retrospective multicenter analysis (FIGHT002A and HOT1301A). Lung Cancer. 2015;90:548-553. doi:10.1016/j. lungcan.2015.10.010

27. Leuzzi G, Lococo F, Alessandrini G, et al. Prognostic impact of node-spreading pattern in surgically treated small-cell lung cancer: a multicentric analysis. Lung. 2017;195:107-114. doi:10.1007/ s00408-016-9954-4
Cancer Management and Research

\section{Publish your work in this journal}

Cancer Management and Research is an international, peer-reviewed open access journal focusing on cancer research and the optimal use of preventative and integrated treatment interventions to achieve improved outcomes, enhanced survival and quality of life for the cancer patient.
The manuscript management system is completely online and includes a very quick and fair peer-review system, which is all easy to use. Visit http://www.dovepress.com/testimonials.php to read real quotes from published authors. 